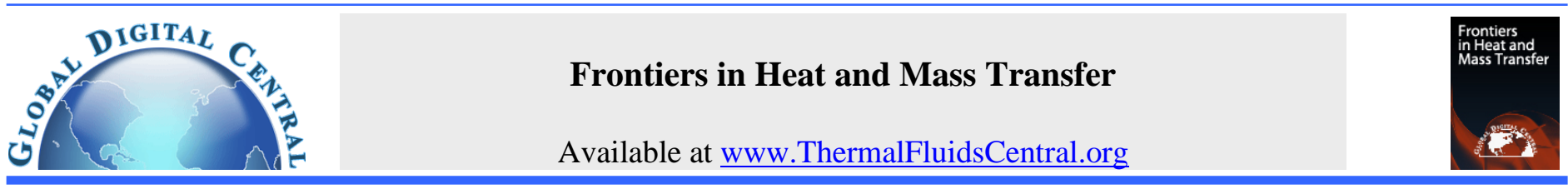

\title{
NUMERICAL ANALYSES ON VAPOR TEMPERATURE DROP IN AN ULTRA-THIN HEAT PIPE WITH A THIN WICK SHEET
}

\author{
Yasushi Koito* \\ Kumamoto University, Kumamoto-shi, Kumamoto, 860-8555, Japan
}

\begin{abstract}
Numerical analyses were conducted for an ultra-thin heat pipe in which a thin wick layer was placed on the bottom. The vapor temperature drop caused by vapor flow friction was discussed for two types of the ultra-thin heat pipes with small and large widths. The numerical results were compared with those obtained for an ultra-thin heat pipe with a centered-wick structure. It was confirmed that the vapor temperature drop was reduced effectively by increasing the width of the heat pipe. Therefore, a wider ultra-thin heat pipe, that is, an ultra-thin vapor chamber is a promising option for nextgeneration thermal management.
\end{abstract}

Keywords: Heat transfer, Thermal design, Ultra-thin heat pipe, Thin wick layer, Vapor chamber

\section{INTRODUCTION}

To meet the increasing demand for cooling thin electronic devices such as smartphones, a centered-wick ultra-thin heat pipe has been used as one of thermal solutions. Many research works related to the centered-wick ultra-thin heat pipe have been published in recent years. Unlike conventional capillary-driven heat pipes, a wick structure is positioned at the center of the heat pipe with vapor flow channels retained on both sides of the wick structure. The fabrication process of the centered-wick ultra-thin heat pipe is simple, that is, a wick structure is inserted within a metal pipe, and the ultra-thin heat pipe is completed by flattening the pipe to a desired thickness. The centered-wick heat pipes are becoming thinner year by year. Recent research works on the centered-wick ultrathin heat pipes were reviewed in the author's previous papers (Koito, 2019a; Koito, 2019b).

Not only the abovementioned centered-wick structure but also thin wick layers are employed within the ultra-thin heat pipes. Like conventional capillary-driven heat pipes, the thin wick layers are used on the inner surface of the heat pipe wall. Dai et al. (2020) fabricated an ultra-thin flattened heat pipe of $80 \mathrm{~mm}$ long, $9 \mathrm{~mm}$ wide, and $1.5 \mathrm{~mm}$ thick. As a wick structure, a layer of wire mesh with the thickness of 0.12 $\mathrm{mm}$ was placed on the inner surface of the flattened heat pipe container. The height of the vapor flow channel was approximately $0.86 \mathrm{~mm}$. Shi et al. (2019) presented an ultra-thin heat pipe of $80 \mathrm{~mm}$ (length) $\times 50 \mathrm{~mm}$ (width) $\times 0.65 \mathrm{~mm}$ (thickness). The height of the vapor flow channel was $0.2 \mathrm{~mm}$. This heat pipe was fabricated by piling up a lower copper foil, a layer of copper wire mesh, and an upper copper foil. Pillars were also used within the vapor flow channel to avoid deformation of the heat pipe container. Chen et al. (2019) made an ultra-thin flat-plate heat pipe of $120 \mathrm{~mm} \times 120 \mathrm{~mm} \times 2 \mathrm{~mm}$ (thickness) by welding two thin containers: an evaporator and a condenser section. A wick structure was fabricated on the inner surfaces of the evaporator and condenser containers. The height of the vapor flow channel was $1 \mathrm{~mm}$.

The use of the centered-wick structure and the thin wick layers is a typical approach in the fabrication of the ultra-thin heat pipes. However, the centered-wick structure restricts the heat pipe width because the wick structure is positioned at the center. Wider ultra-thin heat pipes could be fabricated with the use of the thin wick layers. In the wider heat pipes, a two-dimensional heat transport from an evaporator to a condenser section would occur, resulting in a lower thermal resistance between them. This kind of heat pipe is known as a vapor chamber (Mochizuki and Nguyen, 2019; Bulut et al., 2019; Velardo et al., 2019; Huang et al., 2019; Patankar et al., 2019).

In the thermal design process of ultra-thin heat pipes, it is vital to consider the effect of vapor flow friction on the thermal performance of the heat pipe (Koito, 2019a). The vapor flow friction causes an increase in the vapor temperature drop, resulting in a decrease in the thermal performance. In the author's previous studies (Koito, 2019a; Koito, 2019b), numerical analyses were conducted to clarify the fluid-flow and heat-transport characteristics within centered-wick ultra-thin heat pipes. However, to the author's knowledge, little information has been published on the effect of the vapor flow friction within the ultra-thin heat pipes having thin wick layers. This information is required for rational thermal design of the ultra-thin heat pipes. In this study, therefore, extended three-dimensional numerical analyses were conducted for the ultra-thin heat pipe with a thin wick layer. Two types of the ultra-thin heat pipes with small and large widths were considered. Numerical results of the vapor, pressure, and temperature distributions within the heat pipes were obtained. The numerical results were compared with those obtained for a centered-wick ultra-thin heat pipe. Moreover, discussion was made on two-dimensional heat transport within the ultrathin heat pipes.

\section{MATHEMATICAL MODEL AND NUMERICAL CONDITIONS}

Numerical analyses were conducted in the $x-y-z$ three-dimensional coordinate system. Figure 1 shows a mathematical model of an ultra-thin heat pipe with a thin wick layer. The model was axisymmetric at $x=0$, and comprised a vapor and liquid-wick regions of the same length, $l_{t}$, and width, $w_{t}$. The thickness of the liquid-wick region was $\delta$, and the total 


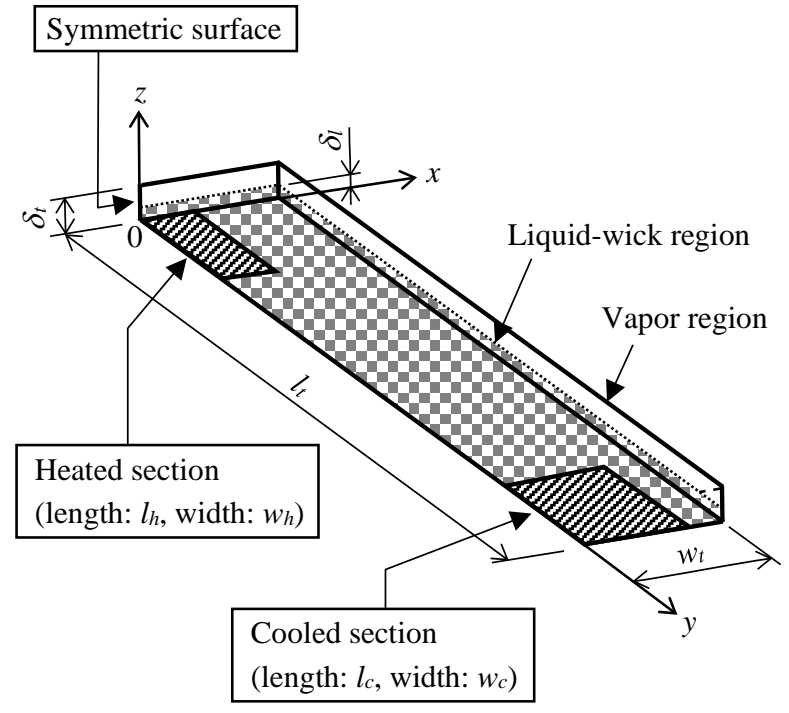

Fig. 1 Mathematical model.

Table 1 Numerical conditions.

\begin{tabular}{|l|l|}
\hline Length of vapor and liquid-wick regions, $l_{t}[\mathrm{~mm}]$ & 100 \\
\hline Length of heated section, $l_{h}[\mathrm{~mm}]$ & 10 \\
\hline Width of heated section, $w_{h}[\mathrm{~mm}]$ & 1.5 \\
\hline Heat input and heat output $[\mathrm{W}]$ & 1.0 \\
\hline $\begin{array}{l}\text { Operating temperature }\left[{ }^{\circ} \mathrm{C}\right] \\
\left(=\text { temperature at } x=w_{t} / 2, y=l_{t} / 2 \text {, and } z=\delta_{l}\right)\end{array}$ & 50 \\
\hline
\end{tabular}

thickness of the heat pipe model was $\delta_{t}$. A heated and cooled sections were located at the bottom of the model. The length and width of the heated section were $l_{h}$ and $w h$, respectively; those of the cooled section were $l_{c}$ and $w_{c}$.

Velocity, pressure, and temperature distributions in the vapor and liquid-wick regions were obtained by conducting numerical calculations. The governing equations and boundary conditions described in the author's previous papers (Koito, 2019a; Koito, 2019b) were applied to corresponding regions and boundaries of the present heat pipe model. Because their details were already presented, only the main features are described below. As the governing equations, the equations of continuity, motion, and energy were applied to the vapor and liquid-wick regions. Heat flux was prescribed at the heated and cooled sections. Except for these sections, an adiabatic condition was employed on the outer surface of the heat pipe model. The Clausius-Clapeyron equation was used to calculate the temperature at the interface between the vapor and liquidwick regions.

The values of $\delta_{l}, \delta_{t}, w_{c}, w_{t}$, and $l_{c}$ were changed under the numerical conditions shown in Table 1. Similar to the author's previous studies (Koito, 2019a; Koito, 2019b), sintered copper powder and water were selected as a wick structure and a working fluid, respectively. In the present numerical analyses, two types of the ultra-thin heat pipes with small and large widths were considered. For the case of the heat pipe with small width, the calculations were conducted under $w_{h}=w_{c}=w_{t}$, implying that the heated and cooled sections were same in width. For the case of the heat pipe with large width, on the other hand, the width of the cooled section was larger than that of the heated section, and the numerical results were obtained under $w_{h}<w_{c}$ and $w_{c}=w_{t}$.

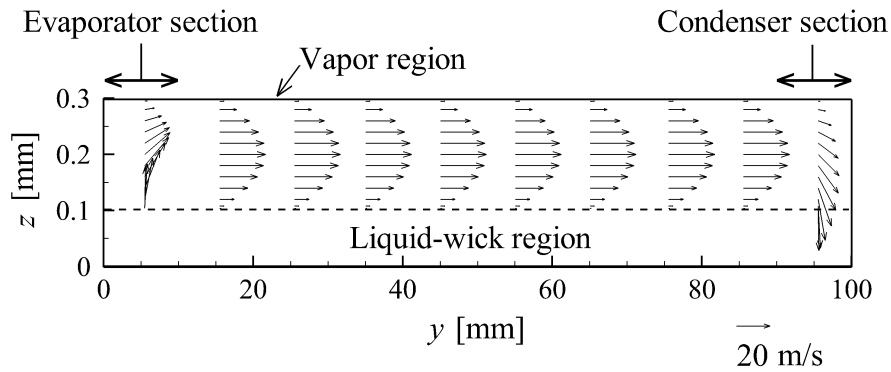

(a) Velocity distribution

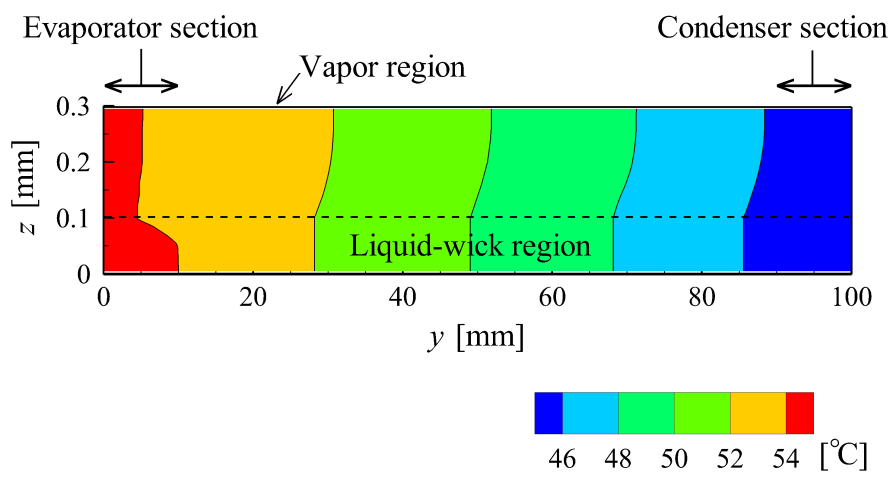

(b) Temperature distribution

Fig. 2 Distributions on the $y-z$ cross-section at $x=0.75 \mathrm{~mm}$ $\left(\delta_{l}=0.1 \mathrm{~mm}, \delta_{t}=0.3 \mathrm{~mm}, w_{c}=w_{t}=1.5 \mathrm{~mm}, l_{c}=10 \mathrm{~mm}\right)$.

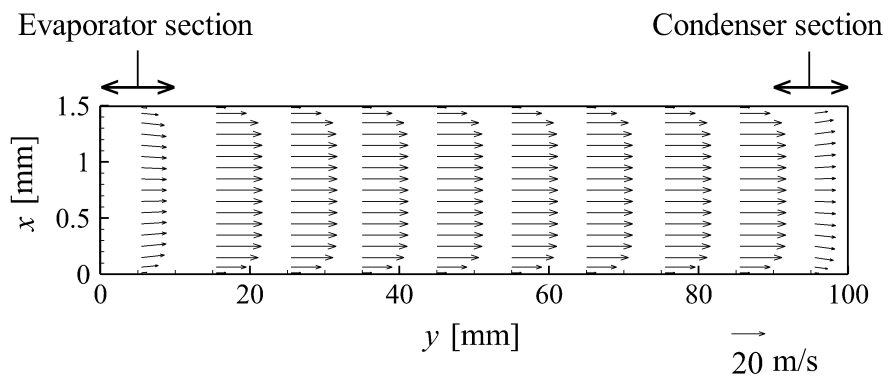

(a) Velocity distribution

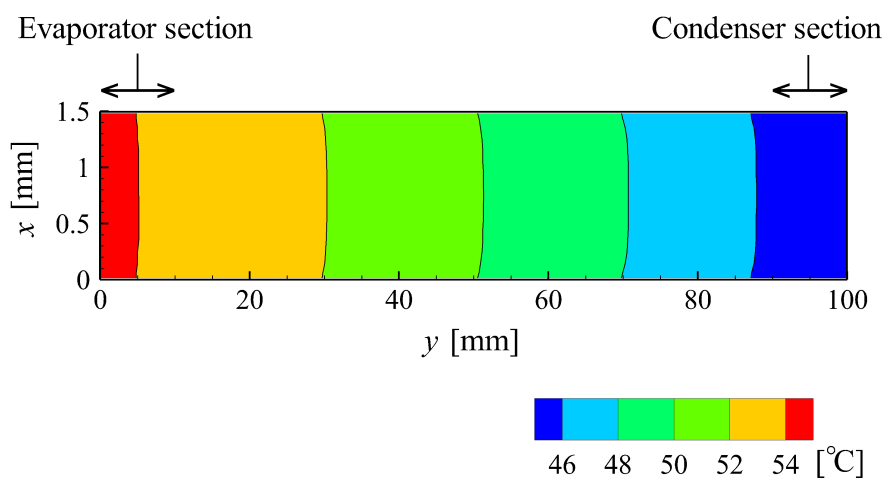

(b) Temperature distribution

Fig. 3 Distributions on the $x-y$ cross-section at $z=0.2 \mathrm{~mm}$ $\left(\delta_{l}=0.1 \mathrm{~mm}, \delta_{t}=0.3 \mathrm{~mm}, w_{c}=w_{t}=1.5 \mathrm{~mm}, l_{c}=10 \mathrm{~mm}\right)$. 


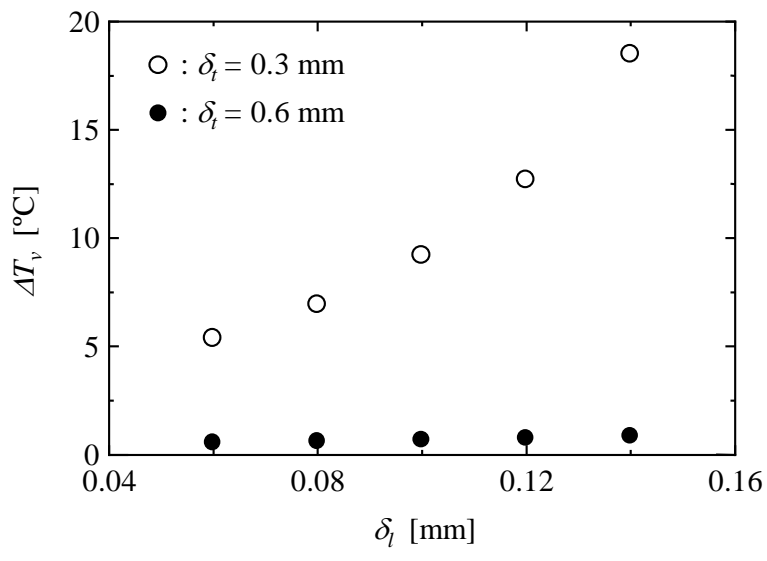

Fig. 4 Vapor temperature differences with respect to the thickness of the liquid-wick region $\left(w_{c}=w_{t}=1.5 \mathrm{~mm}, l_{c}=10 \mathrm{~mm}\right)$.

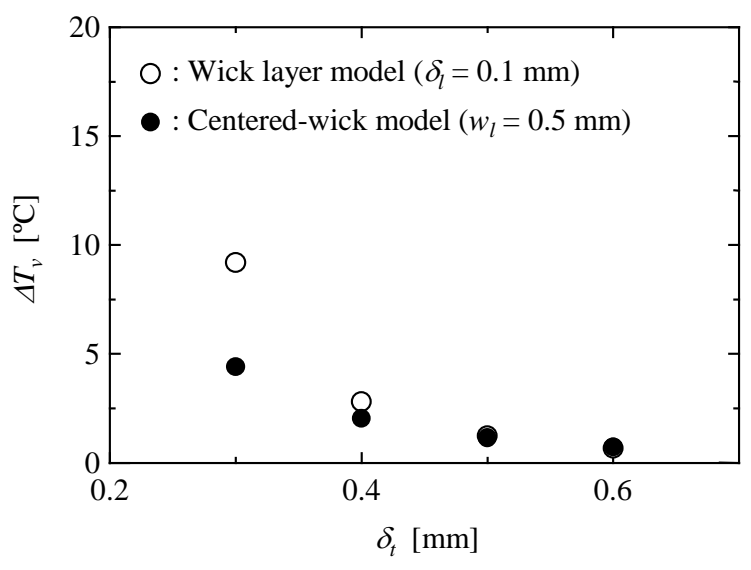

Fig. 5 Vapor temperature differences with respect to the thickness of the heat pipe model $\left(w_{c}=w_{t}=1.5 \mathrm{~mm}, l_{c}=10 \mathrm{~mm}\right)$.

\section{RESULTS AND DISCUSSION}

\subsection{Ultra-thin Heat Pipe with Small Width}

Figure 2 shows the vapor velocity and temperature distributions on the $y-z$ cross-section at $x=0.75 \mathrm{~mm}$. Those distributions on the $x-y$ crosssection at $z=0.2 \mathrm{~mm}$ are shown in Fig. 3. Those numerical results were obtained for $\delta_{l}=0.1 \mathrm{~mm}, \delta_{t}=0.3 \mathrm{~mm}, w_{c}=w_{t}=1.5 \mathrm{~mm}$, and $l_{c}=10$ $\mathrm{mm}$. It should be noted that the thickness in $z$ direction and the width in $x$ direction were enlarged relative to the length in $y$ direction. The dashed lines in Fig. 2 indicate the interface between the vapor and liquid-wick regions. An evaporator and a condenser section are also indicated in those figures. Like conventional capillary-driven heat pipes, a vapor flow from the evaporator to the condenser section was confirmed. In ultra-thin heat pipes, the effect of vapor flow friction is large, and it causes an increase in the vapor temperature drop (Koito, 2019a). Thus, by using the numerical results of temperatures in the vapor region, $T_{v}(x, y, z)$, the temperature difference over the vapor region, $\Delta T_{v}$, was evaluated by the following equation:

$$
\Delta T_{v}=T_{v}\left(w_{t} / 2,0, \delta_{l}\right)-T_{v}\left(w_{t} / 2, l_{t}, \delta_{l}\right)
$$

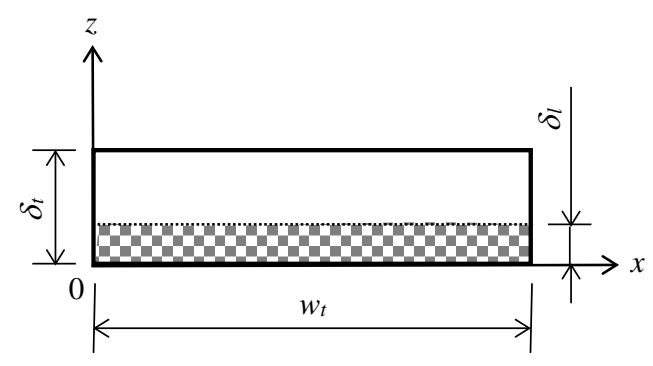

(a) Wick layer model

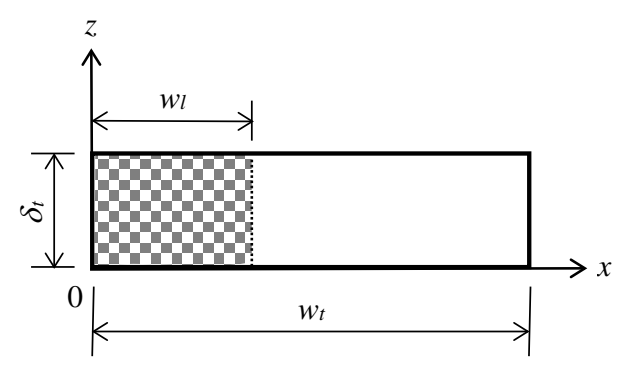

(b) Centered-wick model (Koito, 2019a; Koito, 2019b)

Fig. 6 Wick layer and centered-wick models.

The $\Delta T_{v}$ value in Figs. 2 and 3 was $9.2^{\circ} \mathrm{C}$, whereas the total temperature difference between the heated and cooled sections was $10.7^{\circ} \mathrm{C}$, confirming that the vapor temperature drop was remarkably large within the ultra-thin heat pipe.

Figure 4 shows the $\Delta T_{v}$ values with respect to $\delta_{l}$ for $\delta_{t}=0.3$ and 0.6 $\mathrm{mm}$. Except for $\delta_{l}$ and $\delta_{t}$, the numerical conditions were identical with those in Figs. 2 and 3. Essentially, when $\delta_{t}$ is constant, $\Delta T_{v}$ becomes larger with increase in $\delta_{l}$ because the vapor region narrows. However, the increase in $\Delta T_{v}$ is influenced by the height of the vapor region, ( $\delta_{t}-$ $\left.\delta_{l}\right)$, and it was negligibly small for $\delta_{t}=0.6 \mathrm{~mm}$. The $\left(\delta_{t}-\delta_{l}\right)$ value was $0.5 \mathrm{~mm}$ in this case. For $\delta_{t}=0.3 \mathrm{~mm}$, on the other hand, the $\left(\delta_{t}-\delta_{l}\right)$ value was $0.2 \mathrm{~mm}$, and the increase in $\Delta T_{v}$ was remarkable. Figure 5 shows the relation between $\Delta T_{v}$ and $\delta_{t}$ at $\delta_{l}=0.1 \mathrm{~mm}$. A large increase in $\Delta T_{v}$ was found in the range between $\delta_{t}=0.3$ and $0.4 \mathrm{~mm}$, which corresponded to 0.2 and $0.3 \mathrm{~mm}$ in the $\left(\delta_{t}-\delta_{l}\right)$ value. It is vital to consider such remarkable increase in $\Delta T_{v}$ in the thermal design process of ultra-thin heat pipes.

The $\Delta T_{v}$ values in case of a centered-wick heat pipe are also shown in Fig. 5. Those numerical results were obtained by using the author's previous mathematical model (Koito, 2019a; Koito, 2019b). The present wick layer model and the previous centered-wick model are compared in Fig. 6 . The thickness and width of the two models were identical, and the width of the liquid-wick region in the centered-wick model is denoted by $w_{l}$. The numerical results of the centered-wick heat pipe were obtained by changing $\delta_{t}$ at $w_{l}=0.5 \mathrm{~mm}, w_{t}=1.5 \mathrm{~mm}$, and $l_{t}=100 \mathrm{~mm}$. Besides, $w_{h}=w_{c}=0.5 \mathrm{~mm}, l_{h}=l_{c}=100 \mathrm{~mm}$, and the heat input/output were 1.0 $W$. It should be noted that the $x-z$ cross-sectional areas of the vapor region for the wick layer and centered-wick models were identical at $\delta_{t}$ $=0.3 \mathrm{~mm}$, and the former became larger than the latter with increase in $\delta_{t}$ for $\delta_{t}>0.3 \mathrm{~mm}$. The $\Delta T_{v}$ values of the centered-wick model were calculated by the following equation: 


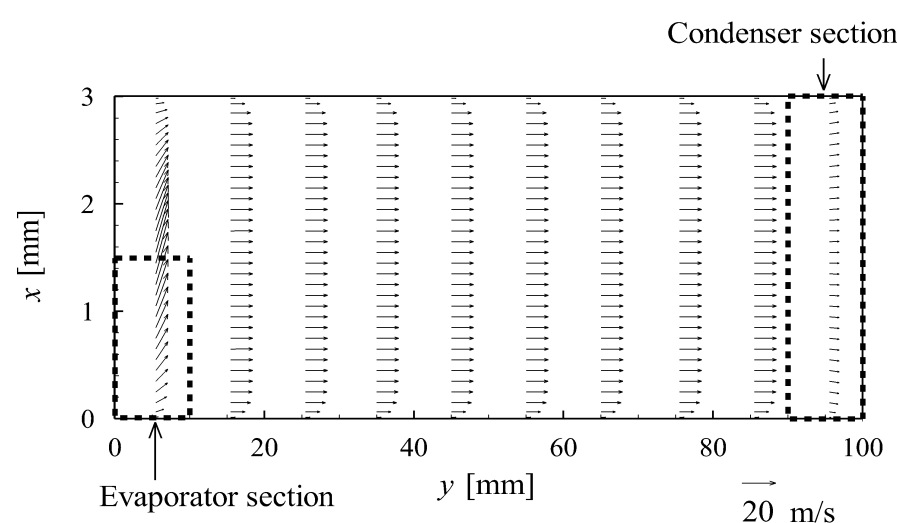

(a) Velocity distribution

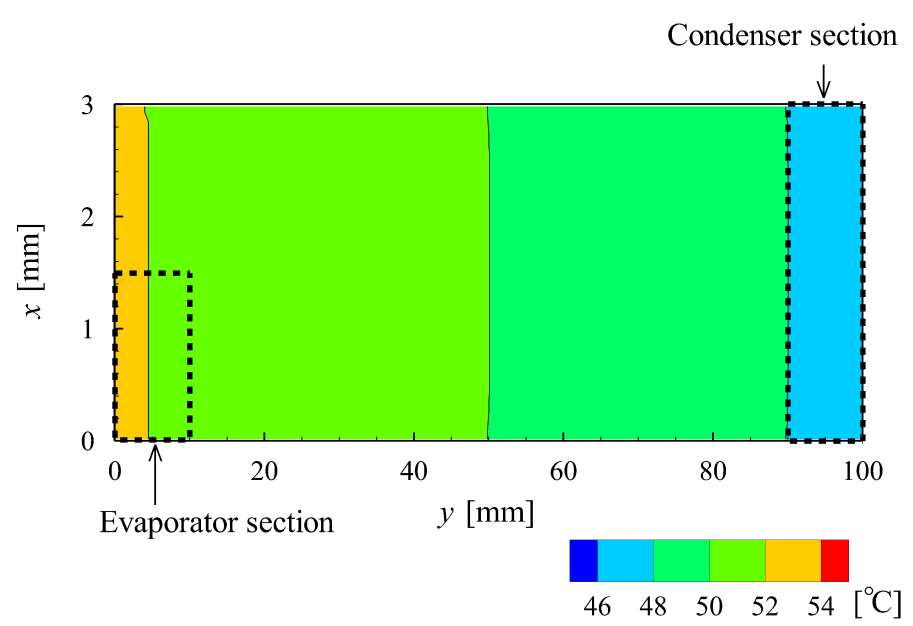

(b) Temperature distribution

Fig. 7 Distributions on the $x-y$ cross-section at $z=0.2 \mathrm{~mm}$ $\left(\delta_{l}=0.1 \mathrm{~mm}, \delta_{t}=0.3 \mathrm{~mm}, w_{c}=w_{t}=3.0 \mathrm{~mm}, l_{c}=10 \mathrm{~mm}\right)$.

$\Delta T_{v}=T_{v}\left(w_{l}, 0, \delta_{t} / 2\right)-T_{v}\left(w_{l}, l_{t}, \delta_{t} / 2\right)$

The difference in $\Delta T_{v}$ between the wick layer and centered-wick models became larger with decrease in $\delta_{t}$, and it was conspicuous at $\delta_{t}=0.3 \mathrm{~mm}$. In this thickness, although the cross-sectional areas of the vapor region were identical, the $\Delta T_{v}$ value for the wick layer model was much larger than that for the centered-wick model. This was because the height of the vapor region for the wick layer model was smaller than that for the centered-wick model. Since the aspect ratio of the cross section was closer to one, the vapor temperature drop within the centered-wick model was smaller than that within the wick layer model.

\subsection{Ultra-thin Heat Pipe with Large Width}

Figure 7 shows the vapor velocity and temperature distributions on the $x-y$ cross-section at $z=0.2 \mathrm{~mm}$ for $w_{c}=w_{t}=3.0 \mathrm{~mm}$. Except for $w_{c}$ and $w_{t}$, the numerical conditions were identical with those in Figs. 2 and 3. It should be noted that the width in $x$ direction was enlarged relative to the length in $y$ direction. As shown in the figures, the condenser section was two times larger than the evaporator section. Different from the velocity distribution in Fig. 3 (a), two-dimensional vapor flow, that is, the vapor flow in $x$ direction as well as that in $y$ direction was found at the evaporator section. Moreover, the vapor velocity in Fig. 7 (a) was

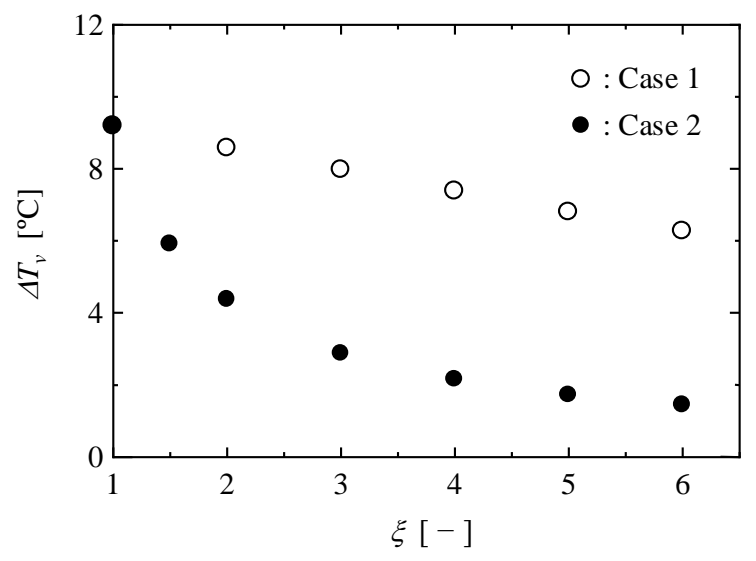

Fig. 8 Reduction in the vapor temperature difference $\left(\delta_{l}=0.1 \mathrm{~mm}, \delta_{t}=0.3 \mathrm{~mm}\right)$.

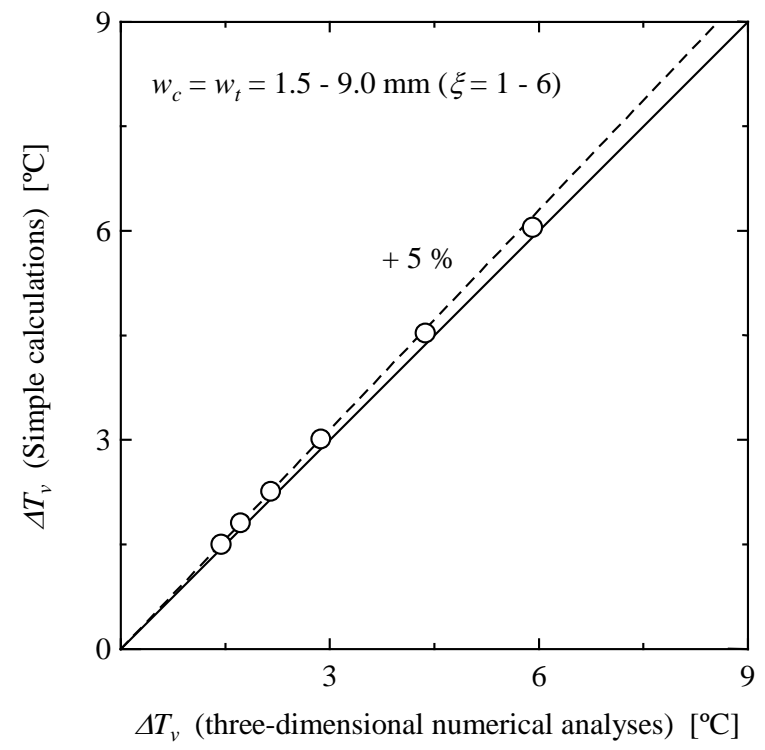

Fig. 9 Comparison between the results of simple calculations and three-dimensional numerical analyses.

lower than that in Fig. 3 (a) because of increase in the cross-sectional area of the vapor region. Thus, the temperature difference over the vapor region in Fig. 7 (b) was smaller than that in Fig. 3 (b).

The ratio of the cooled section area to the heated section area, $\xi$, was calculated by the following equation:

$\xi=\frac{l_{c} w_{c}}{l_{h} w_{h}}$

Figure 8 shows the $\Delta T_{v}$ values with respect to $\xi$. The numerical results were obtained for two cases (Case 1 and Case 2) at $\delta_{l}=0.1 \mathrm{~mm}$ and $\delta_{t}=$ $0.3 \mathrm{~mm}$. In Case $1, l_{c}$ was increased at $w_{c}=w_{t}=1.5 \mathrm{~mm}$, whereas $w_{c}(=$ $w_{t}$ ) was increased at $l_{c}=10 \mathrm{~mm}$ in Case 2. As expected, $\Delta T_{v}$ became smaller with increase in $\xi$; however, the decrease in $\Delta T_{v}$ was much different between the two cases. That is, the decrease in $\Delta T_{v}$ with $\xi$ in Case 2 was much larger than that in Case 1 . Therefore, to reduce the vapor temperature drop within ultra-thin heat pipes, the increase in the width of the cooled section is more effective compared with the increase 
in the length of the cooled section. This is because of the occurrence in the two-dimensional heat transport within the heat pipe. In near future, it is expected that current ultra-thin heat pipes would face heat transport limitation due to further increase in heat generation from thin electronic devices. A wider ultra-thin heat pipe, that is, an ultra-thin vapor chamber is a promising option for next-generation thermal management.

Using the heat input (= heat output), $Q$, the vapor volume flow rate, $V_{v}$, was estimated roughly by the following equation:

$$
V_{v}=\frac{Q}{\rho_{v} h_{f g}}
$$

where $\rho$ is the density and $h_{f g}$ is the latent heat. When one-dimensional vapor flow in $y$ direction between two parallel walls with a gap of ( $\delta_{t}$ $-\delta_{l}$ ) was considered, the vapor pressure gradient was expressed as (Koito, 2019b),

$$
\frac{d p_{v}}{d y}=-\frac{12 \mu_{v} V_{v}}{w_{t}\left(\delta_{t}-\delta_{l}\right)^{3}}
$$

where $\mu$ is the viscosity. The saturated vapor pressure at $x=w_{t} / 2, y=l_{t}$ $/ 2$, and $z=\delta$ l was obtained from the temperature at this point, which was shown in Table 1. Thus, the vapor pressure distribution in the vapor region was calculated with Eqs. (4) and (5), and furthermore, the temperature difference, $\Delta T_{v}$, over the vapor region was obtained by using the Clausius-Clapeyron equation.

Concerning the $\Delta T_{v}$ value, the simple calculation results with Eqs. (4) and (5) were compared in Fig. 9 with the results of three-dimensional numerical analysis. The comparison was made by changing $w_{c}\left(=w_{t}\right)$ at $\delta_{l}=0.1 \mathrm{~mm}, \delta_{t}=0.3 \mathrm{~mm}$, and $l_{c}=10 \mathrm{~mm}$. In the simple calculation, slightly larger vapor pressure drops were obtained at the evaporator and condenser sections because change in the vapor velocity in $y$ direction was neglected. Thus, the $\Delta T_{v}$ value for the simple calculation was slightly higher than that for the three-dimensional numerical analysis. However, in the present calculation range, their difference was less than $5 \%$, implying that the present simple calculation method is effective for the estimation of the vapor temperature difference within ultra-thin vapor chambers.

\section{CONCLUSIONS}

Numerical analyses were conducted for an ultra-thin heat pipe with a thin wick layer. Two types of the heat pipes with small and large widths were considered. Discussion was made on the vapor temperature drop within the heat pipe, which was caused by vapor flow friction. Findings in this study were summarized as follows:

- For the case of the ultra-thin heat pipe with small width, and moreover the heated and cooled sections are same in width, the use of the centered-wick structure is recommended rather than the thin wick layers to reduce the vapor temperature drop within the heat pipe.

- Wider ultra-thin heat pipes could be fabricated with the use of the thin wick layers. Because two-dimensional heat transport occurs, the increase in the width of the cooled section is effective to reduce the vapor temperature drop within the heat pipe. This is more effective compared with the increase in the length of the cooled section. Therefore, a wider ultra-thin heat pipe, that is, an ultra-thin vapor chamber is a promising option for next-generation thermal management.

- The simple calculation method shown in this study is useful for the estimation of the vapor temperature drop within the ultrathin vapor chambers.

\section{NOMENCLATURE}

$\begin{array}{ll}h_{f g} & \text { latent heat }(\mathrm{J} / \mathrm{kg}) \\ l & \text { length }(\mathrm{mm}) \\ p & \text { pressure }(\mathrm{Pa}) \\ Q & \text { heat input, heat output }(\mathrm{W}) \\ T_{v} & \text { vapor temperature }\left({ }^{\circ} \mathrm{C}\right) \\ V & \text { volume flow rate }\left(\mathrm{m}^{3} / \mathrm{s}\right) \\ w & \text { width }(\mathrm{mm}, \mathrm{m}) \\ x, y, z & \text { three-dimensional coordinate }(\mathrm{mm}, \mathrm{m})\end{array}$

\section{Greek Symbols}

$\Delta T_{v} \quad$ vapor temperature difference $\left({ }^{\circ} \mathrm{C}\right)$

$\delta \quad$ thickness (mm, m)

$\mu \quad$ viscosity (Pa.s)

$\rho$ density $\left(\mathrm{kg} / \mathrm{m}^{3}\right)$

$\xi \quad$ ratio

Subscripts

c cooled section

h heated section

l liquid-wick region

$t$ total

$v \quad$ vapor region

\section{REFERENCES}

Bulut, M., Kandlikar, S. G. and Sozbir, N., 2019, “A Review of Vapor Chambers,” Heat Transfer Engineering, 40, 1551-1573. https://doi.org/10.1080/01457632.2018.1480868

Chen, G., Tang, Y., Wan, Z., Zhong, G., Tang, H. and Zeng, J., 2019, "Heat Transfer Characteristic of an Ultra-thin Flat Plate Heat Pipe with Surface Functional Wicks for Cooling Electronics," International Communications in Heat and Mass Transfer, 100, 12-19. https://doi.org/10.1016/j.icheatmasstransfer.2018.10.011

Dai, X., Tang, Y., Liu, T. and Wang, S., 2020, "Experimental Investigation on the Thermal Characteristics of Ultra-thin Flattened Heat Pipes with Bending Angles,” Applied Thermal Engineering, 172, 115150. https://doi.org/10.1016/j.applthermaleng.2020.115150

Huang, G., Liu, W., Luo, Y., Li, Y. and Chen, H., 2019, "Fabrication and Thermal Performance of Mesh-type Ultra-thin Vapor Chambers," Applied Thermal Engineering, 162, 114263.

https://doi.org/10.1016/j.applthermaleng.2019.114263

Koito, Y., 2019a, “Numerical Analyses on Heat Transfer Characteristics of Ultra-thin Heat Pipes: Fundamental Studies with a Three-dimensional Thermal-fluid Model,” Applied Thermal Engineering, 148, 430-437. https://doi.org/10.1016/j.applthermaleng.2018.10.119

Koito, Y., 2019b, “Numerical Analyses on Vapor Pressure Drop in a Centered-wick Ultra-thin Heat Pipe," Frontiers in Heat and Mass Transfer, 13, 26. https://doi.org/10.5098/hmt.13.26

Mochizuki, M. and Nguyen, T., 2019, "Review of Various Thin Heat Spreader Vapor Chamber Designs, Performance, Lifetime Reliability and Application,” Frontiers in Heat and Mass Transfer, 13, 12. https://doi.org/10.5098/hmt.13.12

Patankar, G., Weibel, J. A. and Garimella, S. V., 2019, “On the Transient Thermal Response of Thin Vapor Chamber Heat Spreaders: Governing Mechanisms and Performance Relative To Metal Spreaders," International Journal of Heat and Mass Transfer, 136, 995-1005. https://doi.org/10.1016/j.ijheatmasstransfer.2019.03.058 
Shi, B., Zhang, H., Zhang, P. and Yan, L., 2019, "Performance Test of an Ultra-thin Flat Heat Pipe with a $0.2 \mathrm{~mm}$ Thick Vapor Chamber," Journal of Micromechanics and Microengineering, 29, 115019. https://doi.org/10.1088/1361-6439/ab42b3
Velardo, J., Date, A., Singh, R., Nihill, J., Date, A. and Phan, T. L., 2019, "On the Effective Thermal Conductivity of the Vapour Region in Vapour Chamber Heat Spreaders,” International Journal of Heat and Mass Transfer, 145, 118797.

https://doi.org/10.1016/j.ijheatmasstransfer.2019.118797 